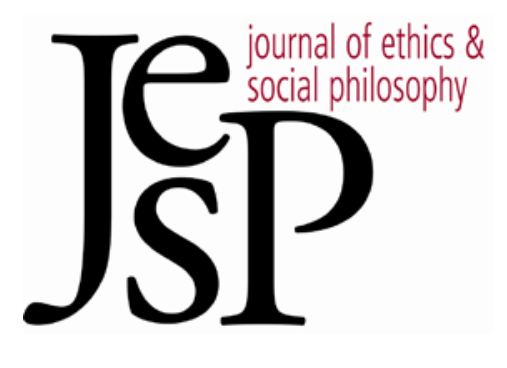

\title{
Depression and the Problem of Absent Desires
}

\author{
BY IAN TULLY
}

JOURNAL OF ETHICS \& SOCIAL PHILOSOPHY

VOL. 11, No. 2 | FEBRUARY 2017 URL: WWW.JESP.ORG COPYRIGHT (C) IAN TULLY 2017 


\title{
Depression and the Problem of Absent Desires
}

\author{
Ian Tully
}

\author{
TN HIS ESSAY, "DEPRESSION, TOO, IS A THING with Feathers," \\ Andrew Solomon paints a particularly vivid picture of what it is like to \\ suffer from depression:
}

\begin{abstract}
I didn't feel very excited or enthusiastic about any of the things that had previously filled me with joy and pleasure. I remember particularly that, coming home and listening to the messages on my answering machine, I would feel tired instead of being pleased to hear from my friends, and I'd think, That's an awful lot of people to have to call back." I was publishing my first novel at the time, and it came out to rather nice reviews. I simply didn't care. All my life I had dreamed of publishing a novel, and now here it was, but all I felt was nullity. That went on for quite a while.
\end{abstract}

Then the sense of life's being effortful kicked in. Everything began to seem like such an enormous, overwhelming effort. I would think to myself, Oh, I should have some lunch. And then I would think, But I have to get the food out. And put it on a plate. And cut it up. And chew it. And swallow it. And it all began to seem like the stations of the cross (Solomon (2008)).

It is plain that Solomon's life, when suffering from depression, is going very badly for him. Yet, surprisingly, depression - a paradigmatic state of ill-being has not been much investigated by philosophers thinking about welfare. In part, this may be because theories of ill-being have received less attention from philosophers than theories of wellbeing have (Kagan (2015)). But whatever its explanation, this lacuna in the literature is unfortunate, for depression has much to teach us about what makes our lives go well - and poorly. In fact, I argue that certain cases of severe depression provide a counterexample to desire-based theories of welfare. A desire-based theory of welfare (which I will also refer to as the "desire view" or the "desire theory") cannot explain why severe depression is bad for us; instead, such a theory implies, implausibly, that certain severely depressed individuals are no longer even subjects of welfare. For these reasons, desire-based theories of welfare should be rejected.

In order to demonstrate this, I first show that the cases of severe depression I highlight pose a problem for a simple version of the desire theory (what I will call the "Simple View"), which I characterize in section 1. After explaining why severe depression is a problem for the Simple View, I go on, in section 3 , to consider more sophisticated versions of the desire theory, which one might hope could avoid the problem I have identified. However, either these modified accounts fail to solve the problem or else they generate other objections that render them unacceptable. As a result, no version of the desire theory is found to be acceptable.

This result is both surprising and important. The desire-satisfaction theory is often seen as the "theory to beat" in the wellbeing literature (Haybron (2008: 3)). Moreover, though many objections have been leveled against desire-based 
accounts of welfare, the problem discussed in this paper is, to my knowledge, a novel one. My conclusion, if true, also points to a more general moral - one stressed recently by Shelly Kagan - that philosophers interested in wellbeing would do well to also attend to instances of our lives going poorly.

\section{Desire-Based Theories of Welfare}

Desire-based theories of wellbeing have a long history and numerous defenders (Hobbes (1994/1651); Brandt (1966); Singer (1979); Heathwood (2006; 2011)). Chris Heathwood describes their core commitments as follows:

The desire-fulfillment theory ... holds, in its simplest form, that what is good in itself for people and other subjects of welfare is their getting what they want, or the fulfillment of their desires, and what is bad in itself for them is their not getting what they want, or the frustration of their desires (Heathwood (2015: 135)).

Thus, for instance, if I want my favorite song to come on the radio and it does, my life goes better for me. Conversely, if I desire to see my favorite band in concert but their show is sold out, it goes worse.

The simplest version of the desire theory that I will be working with in this paper - i.e., the Simple View - has the following three features. ${ }^{1}$ First, on this view, it is only the satisfaction or frustration of a person's actual desires that affect her wellbeing, as opposed to some idealized set of those desires - for example, only her fully informed desires. Second, on the Simple View, it is only the satisfaction or frustration of those desires a person currently holds that makes his life go better or worse for him. In other words, the Simple View incorporates a "temporal concurrence requirement" (Lin (2016: 105)). What this requirement means is that if I desire to have a baked potato now but have ceased to desire it by the time it is done, then eating the potato will no longer improve my wellbeing. A person's desire must be temporally concurrent with its satisfaction (or its frustration) for that satisfaction (or frustration) to be good (or bad) for her. Third, and finally, the Simple View is restricted to present-directed desires - that is, only the satisfaction or frustration of desires a person has concerning the present count with respect to her wellbeing. For example, if I have a desire that I now be listening to Mozart and that desire is frustrated, then my life goes worse.

Put briefly, according to the Simple View, the only desires that are relevant to my welfare are the actual, present-directed desires I am currently expe-

1 A further complication concerns the choice between an "objective" and a "subjective" formulation of the desire view (Lin (2016: 104-5)). According to the "objective" account, what is basically good for us are desire satisfactions - that is, "states of the form p and you desire p." According to the subjective formulation, however - as first sketched by Heathwood - it is subjective desire satisfactions, "events of the form you believe $\mathrm{p}$ and you desire p" that are the basic goods (ibid.: 104; cf. Heathwood (2006: 548)). I believe that the problem I raise in this paper is a problem for either formulation, so I leave it aside in what follows. 
riencing. If I am currently desiring a chocolate donut and get it, that is an instance of desire fulfillment that improves my wellbeing. And if I would strongly like, at this very moment, for my headache to stop, but it does not, this makes my life go worse for me. Later I will entertain versions of the desire theory that allow the satisfaction or frustration of past, idealized or even masked desires to affect wellbeing. For now, however, I merely want to raise a problem for the Simple View.

Before moving on to that problem, however, I should address a potential concern one might have with my project. A chief part of my complaint against the desire theory is that it cannot explain the badness of certain instances of severe depression. But someone might think that the desire theorist can simply reject this explanatory burden. He might hold, instead, that the desire theory is simply a theory of wellbeing, and that it has nothing to say about what makes life go badly. ${ }^{2}$

Now, from Heathwood's characterization of the desire theory above, it seems evident that the theory is typically thought to have something to say about both wellbeing and ill-being. With that said, it is still possible for a defender of the desire theory to hold that the typical view is wrong: the desire theory, she might insist, ought to be seen as a theory of wellbeing alone. Suppose we go along. There are two ways that theories of wellbeing could relate to theories of ill-being: either the theories are symmetrical or they are asymmetrical. If the former, then what makes our lives go badly is the converse of what makes our lives go well: for instance, desire frustration, the (apparent) converse of desire satisfaction, makes our lives go badly. If the theories are asymmetrical, however, then the two theories are independent of one another - that is, the explanation of what makes our lives go badly is independent of the explanation of what makes our lives go well. We could imagine, for instance, that desire satisfaction makes one's life go well, but pain (where this is not understood in motivational/conative terms) makes one's life go poorly.

Our interlocutor is therefore claiming that we should treat the desire theory asymmetrically. Desire satisfaction makes our lives go well, but something else makes them go poorly. ${ }^{3}$ Now, if the only way to resist the argument of this paper is for the desire theorist to "go asymmetrical," that would be an interesting result in its own right. However, I do not think this gambit will work, for two reasons. First, an asymmetrical theory is a very strange outcome. One reason to think so is that wellbeing and ill-being are opposites: if one is (allthings-considered) well-off, one cannot simultaneously be (all-things-considered) badly off. Since these states are opposites, it is reasonable to expect their determinants to be opposites, too. That would explain why one excludes the

2 Thanks to an anonymous referee for pressing me to consider this possibility more thoroughly.

${ }^{3}$ One could also hold that nothing (properly speaking) makes our lives go poorly, for ill-being is merely the absence of wellbeing (cf. Augustine (1996)). I ignore this possibility in what follows. 
other: a state of net desire satisfaction cannot be a state of net desire frustration, too. But if the determinants of wellbeing and ill-being are not opposites, then it would seem possible to be both high in all-things-considered wellbeing and in all-things-considered ill-being. We should seek to avoid this result.

Second, and more importantly, even granting the intuitive plausibility of an asymmetrical theory of welfare, the argument of this paper still has bite. That is because, as I will go on to show, the desire theorist is still forced to claim that nothing can benefit certain of those who are severely depressed. This is still a highly implausible result; thus, my argument still cuts against the desire theory even conceived merely as a theory of wellbeing.

\section{Depressive Anhedonia and Absent Desires}

As noted in the introduction, I take it as uncontroversial that suffering from depression makes a person's life go worse for her, and that severe depression is a worse state to be in than mild depression. ${ }^{4}$ A case of depression like that described so vividly by Solomon is not a peripheral or complicated case about which intuitions might reasonably differ. If the desire view cannot accommodate this fact, it is in trouble.

Clinical depression comes in a variety of different forms and involves many different symptoms. Here I am chiefly concerned with one aspect of depression in particular: anhedonia. For the purposes of diagnosis, the Diagnostic and Statistical Manual of Mental Disorders (DSM) defines anhedonia as a "markedly diminished interest or pleasure in all, or almost all, activities most of the day, nearly every day" (American Psychiatric Association (2013)). This aspect of depression is made vivid in the quote from Solomon with which I began the paper. Completing his novel (a longstanding goal) and receiving positive reviews of it gave him no joy; he felt no motivation to return friends' phone calls or even to make himself lunch. All he felt was "nullity."

Implicit in the DSM definition are two dissociable forms of anhedonia motivational and consummatory (Treadway and Zald (2011)). A person is experiencing the former when she feels little or no motivation to do things she formerly enjoyed; she is experiencing the latter when formerly pleasant activities or experiences produce little or no pleasure. In more colloquial terms, one might experience a deficit in wanting (motivational anhedonia) or a deficit in liking (consummatory anhedonia).

Some depressed individuals suffer from motivational anhedonia without experiencing a corresponding deficit in consummatory pleasure: they anticipate little or no enjoyment from various activities or experiences, but still enjoy them when they get them (Sherdell, Waugh and Gotlib (2012)). In these cases,

${ }^{4}$ This does not mean that I deny that depression ever has instrumental benefits. Sometimes it does. For example, it can serve as an indication that something has gone deeply wrong in one's life (Andrews and Thompson (2009)). Moreover, depression can plausibly be a merited response to circumstances (Graham (1990)). But none of this is incompatible with claiming that depression - particularly when it is severe - is a paradigmatic state of ill-being. 
it is somewhat unclear whether to say that the individuals have lost their desires; though they lack motivation for certain goals, they still enjoy those goals upon obtaining them. In some instances of major depression, however, both forms of anhedonia are present (Nakonezny et al. (2010); Li et al. (2015)). These cases suggest a clearer picture of desire loss: when a person suffers from deficits in experienced pleasure, then experiences or activities she was formerly motivated to pursue will lose some of their luster - she will anticipate less enjoyment from them going forward. This diminished anticipatory pleasure in turn feeds a motivational deficit. As this process iterates, a person will naturally become less and less motivated to pursue that which formerly gave her pleasure.

In short, as decreases in positive reinforcement inform anticipation of future positive outcomes, decreased motivation may result. Over time, a person can lose his motivation for the goal entirely. Thinking about the goal engenders no anticipated enjoyment; it presents itself as pointless, barren. Thus, he ceases to desire it. I take it that this is more clearly a picture of desire loss because in these cases the individual has no motivation to pursue or bring about the goal, and the individual does not enjoy the goal upon obtaining it. ${ }^{5}$ Thus, both those who take pleasure and those who take motivation as central to desire should be happy (cf. Schroeder (2006)). ${ }^{6}$

If this process is relatively localized, the scope of a person's desire loss is small, and so minimally disrupting to a person's life. In some cases, however, this process is not localized. It is cases like those to which I now turn.

\footnotetext{
${ }^{5}$ Here some may be tempted to object that depression does not cause one to lose one's desires; rather, it masks them. The depressed are, say, still disposed to get pleasure from obtaining various goals, but because of their depression this disposition is unable to manifest. I postpone discussion of this worry until section 3 .

${ }^{6}$ On the other hand, Timothy Schroeder (2004) has defended a more neuroscientifically sophisticated account of desire on which the kind of depression I have sketched here need not be seen as resulting in the loss of desire. As he puts it, a theory of the kind he develops "is committed to holding that a desire can exist in a creature that cannot, by its nature, move or feel" (Schroeder $(2015, \mathbb{S} 1.5)$ ). This is, as I understand it, because of the way in which Schroeder understands the concept of "reward," which he does not treat as synonymous with "pleasure" (2004; 2006: 635-37). I think a full discussion of these issues would take me a bit too far afield; here I will simply note that if Schroeder's view of desire is correct, then it may well furnish a reply on behalf of the desire theorist, but also that his view is controversial, for it is quite revisionary, and thus very far removed from the commonsense picture of desire as he himself notes $(2015, \mathbb{S} 1.5$; see also Brook (2006)). In addition, one might wonder how the satisfaction of a desire that bears no necessary connection to motivation or pleasure could really be good for an agent. So even if Schroeder is right about what desires are, his view might not be a friendly one for desire theorists.
} 


\subsection{The Problem of Absent Desires}

Sometimes anhedonia can be quite general, encompassing, as Solomon makes clear, even such basic desires as the desire to eat something for lunch. When depression gets this bad, simple tasks like getting out of bed or taking a shower become challenging. A kind of total motivational paralysis sets in.

Given that anhedonia can be this general, it seems possible that a person might become so mired in apathy that she ceases to have any desires at all. In fact, such cases are more than merely possible - there are, I contend, actual cases of what we can call complete conative collapse. Viktor Frankl's description of certain victims of the Nazi concentration camps provides illustration of the sort of depression I have in mind. About these individuals Frankl writes:

The day would come when [they] would simply lie on their bunks in the barracks, would refuse to rise for roll call or for assignment to a work squad, would not bother about mess call, and ceased going to the washroom. Once they had reached this state, neither reproaches nor threats could rouse them out of their apathy. Nothing frightened them any longer; punishments they accepted dully and indifferently, without seeming to feel them. (Frankl (1986: 117), quoted in Ghaemi (2013: 94)).

Frankl refers to such a state as "melancholia anesthetica" and regards it with the greatest horror (1986: 128). It therefore seems that a state of complete apathy - of total desirelessness - is not only conceivable, but actual.

Individuals suffering from a condition like that described by Frankl seem plainly to be very badly off. It seems appropriate to pity them; if given the choice, no healthy person would choose to trade places with them.7 Though a state of utterly desirelessness is sometimes taken to be a goal worth aspiring to (at least, on some probably mistaken interpretations of Buddhist doctrine) reflecting on Frankl's concentration camp victims indicates that to be in such a state is actually to be doing very poorly. ${ }^{8}$

Yet about this state the desire theory is silent. According to the simple version of the theory we are currently considering, these individuals no longer possess desires that can be frustrated, as is evidenced by their indifference not only to the demands placed upon them, but even to their bodily functions, to threats and to physical pain. If no desires are being frustrated, then the desire theory has no grounds for ascribing ill-being. But it is simply not plausible to suppose that those individuals Frankl observed in the Nazi camps were not in a terrible state. Indeed, the desire theory would seem to have no grounds for

\footnotetext{
7 Here I am setting aside the question of whether other victims of the camps might rationally prefer to take their places, given that they - the totally desireless - seem at least to no longer be feeling any pain.

8 Some readers may be put in mind here of Nietzsche's criticisms of the Buddhist goal of nirvana, understood as the complete absence of desire (Panaioti (2013)). Whether this an accurate interpretation of Buddhist doctrine or not, the horror which those like Nietzsche feel when contemplating a state of utter desirelessness suggests precedent for regarding states of absent desire as states of ill-being.
} 
treating Frankl's concentration camp victims as subjects of welfare ascription at all. As a result, the desire theorist seems forced to hold that the victims Frankl describes cannot be benefited, and therefore that freedom from their hellish circumstances would not be good for them, given that they have long since ceased to desire it. Further, the desire theorist must maintain that nothing further can go badly for them. If they are physically assaulted by guards, for instance, then they are not made worse off. But these conclusions are absurd.

Call this the "problem of absent desires." Note that this problem is different from other cases of "absent desires." Accounting for posthumous harms, for example, poses a similar sort of challenge for desire-based theories of welfare (Portmore (2007)). Yet it is not so implausible to bite the bullet and concede that the dead cannot be harmed (or benefited): if the dead have ceased to exist, one might argue that there is no subject who could be harmed by the frustration of the deceased's antemortem aims. ${ }^{9}$ For the severely depressed, however, such a response is not plausible. These are still living, breathing human beings; there is still clearly a subject of harm here.

Someone might also be tempted to draw an analogy between the severely depressed prisoners and individuals in a "persistent vegetative state" (PVS). They might argue that it is not so implausible to suppose that PVS patients cannot be benefited or harmed; thus, we should not be troubled by an argument that reaches the same conclusion with respect to certain of the severely depressed. But here, too, the analogy does not hold. Such conclusions are controversial even with respect to PVS patients, who lack all conscious experience whatsoever (The Multi-Society Task Force on PVS (1994)). But consider how striking it would be to make a similar claim with respect to the severely depressed prisoners. These individuals retain conscious experience: they are aware of themselves and their surroundings, and we have no reason to suppose that their depression has rendered them incapable of interpersonal interaction. Though they lack desire, they retain many of the elements of mental life that PVS patients lack; thus, the analogy fails. It is therefore a far greater stretch to conclude that the prisoners are beyond welfare ascription than to say the same of PVS patients.

I contend that this problem makes what I have called the "Simple View" unacceptable. The concentration camp victims are in a very bad state, but they are not suffering any actual, concurrent, present-directed desire frustration. In what follows, I show that the problem extends to desire-based theories generally - that is, to those that modify the Simple View. Either the modifications fail to deal with the problem I have identified, or else they come at too great a cost, incurring additional problems that make them unacceptable.

${ }^{9}$ Not that this is the end of the story. See Bradley (2009) for a thorough discussion of the issue of posthumous harm. 


\section{Objections}

Second-order desires. The first objection to my argument turns on the distinction between first-order and second-order desires. A second-order desire is a desire that one have some first-order desire - say, a desire that one desire another's wellbeing (Frankfurt (1971)). Perhaps depression suppresses first-order desires while leaving second-order desires untouched. If this is right, then the defender of the desire theory could argue that the severely depressed remain welfare subjects. Things go poorly for them insofar as their second-order desires are frustrated.

It is certainly true that milder cases of depression may often involve a great deal of second-order desire frustration: as a person loses his desire to go to work or take care of his appearance, for instance, he may accordingly develop second-order desires that those first-order desires be restored. ${ }^{10}$ Without treatment, however, his first-order desires are likely to continue to be frustrated. This is plainly a bad state for a person to be in.

However, I resist the conclusion that the desire theorist can escape the problem of absent desires by appealing to second-order desires for the following reason. Many animals (and small children) can experience depression (Rottenberg (2014: 39-56)), but it is plausible that they lack higher-order thought. Now, imagine that as a result of mistreatment a nonhuman animal is brought to the same state of profound depression that the concentration camp victims experienced. Appealing to frustration of second-order desires will not explain why it is bad for the animal to experience this sort of depression. (Nor can second-order desires explain why such a creature remains a welfare subject.) But as with the victims Frankl describes, I assume such a state is bad for a creature to experience, human or not. So frustration of second-order desires cannot account for its badness.

Idealized desires. As noted above, according to the Simple View, what is good for a person is what that person actually wants. Yet actual-desire versions of desire-satisfaction theory are faced with certain problems. For example, a person may actually desire to eat a slice of pie, not knowing that the pie will actually cause him to have a severe allergic reaction (Heathwood (2015: 139)). It seems that if he gets what he actually wants, he will be made worse off. Because of problems like this, some philosophers opt for idealized versions of the desire theory (Rawls (1971); Railton (1986)). One way of idealizing desires is to appeal to an ideal advisor, a fully informed and rational version of oneself. According to Peter Railton's version of this view, "an individual's good consists in what he would want himself to want, or to pursue, were he to contemplate his present situation from a standpoint fully and vividly informed about himself and his circumstances, and entirely free of cognitive error or lapses of instrumental rationality" (ibid.: 16). Since my ideal advisor is fully informed, he

10 But, of course, he does not have to develop them: he made have simply had certain secondorder desires all along. 
would not want me to eat the slice of allergenic pie; thus, satisfying my desire to eat the pie is not good for me.

Perhaps appealing to an ideal advisor can save the desire theory from the argument in this paper. We can grant that the current selves of Frankl's concentration camp victims have no desires and yet appeal to the desires of idealized versions of these individuals to explain what is nevertheless good and bad for them. Their nonidealized selves may want nothing, but their idealized selves may want them to be liberated. Thus, liberation would be good for them.

One thing to note here is that making this move pushes desire theorists toward giving up (or at least weakening) the so-called "resonance constraint," (Rosati (1995)). Suppose, for example, that my ideal advisor wants me to change careers. Yet from my actual, benighted state, I cannot be made to desire the career path that my ideal advisor desires for me. Were I fully informed and rational, then I would desire it, but since I am rather far from either state, I do not and, indeed, cannot desire it (cf. Rosati (1995: 299-314)). ${ }^{11}$ Therefore, I am, as Railton puts it, "alienated" from my own wellbeing (Railton (1986: 9)). If only views that abandon (or weaken) this constraint can accommodate the problem of this paper, that is an interesting result given its fairly widespread endorsement.

With that said, such a view might still seem to return the conclusion that nothing is good or bad for Frankl's concentration camp victims. This is because an ideal advisor needs some raw material with which to work - that is, one's idealized self merely shapes, organizes and makes coherent one's set of actual desires. If one has no actual desires to begin with, then adding full information and rationality is not going to generate new ones. To see this, suppose I am someone in the concentration camp. My fully informed advisor knows, let us say, that I will soon be liberated. He knows that the war will be over soon and that there are many opportunities for me in the postwar world. His powers of reasoning are unimpaired. But how does he get from these beliefs (plus his intact powers of reasoning) to desires for his unidealized self? I do not care that I will soon be liberated; why, then, would he? The (Humean) thought here is simply that beliefs and reason alone are insufficient to produce intrinsic desires. There is thus no desire set to be made ideal; given that a person wants nothing whatsoever, her fully informed and rational self will also want nothing. The problem appears to simply reemerge at a new level.

Past desires. But perhaps this is too quick. Maybe my ideal advisor's raw material is not as impoverished as I have been claiming. I used to desire things, after all, so maybe we can include past desires in the mix. One thing I used to like to do, for example, is spend time with my family. My ideal advisor knows I will soon be liberated, and that my family is still alive, etc. This knowledge, along with my past desire to spend time with my family, might allow my ideal advisor to form the desire that I be liberated (since liberation will allow me to

${ }^{11}$ As Connie Rosati puts the worry, “the 'fully informed person,' though purportedly you, may not be someone whose judgments you would recognize as authoritative" (1995: 299). 
spend time with them, and I used to like doing that). Thus, liberation would be good for me.

Now, making this move requires abandoning the temporal concurrence requirement discussed above. Abandoning this requirement produces problems, however (cf. Parfit (1984); Portmore (2007)). ${ }^{12}$ When I was a child I had all sorts of desires the satisfaction of which now would not be good for me. For instance, I formerly desired to listen to bad mid-'90s pop music, but no longer do. Why is listening to that music no longer good for me? The most plausible answer (from a desire-based theory of wellbeing) seems to be because I no longer have a desire to listen to it. I have grown up. Now, if satisfying a past desire is no longer good for me when the desire is absent, then the proposal above would seem imperiled. After all, the concentration camp victims have no desires, and so satisfying past desires would not be good for them any more than satisfying my discarded childhood desires would be good for me. Alternatively, one might put the point by saying that, given that my childhood desires for various things give me no reason to pursue those goals in the present, the concentration camp victims' past desires to see their families give them no reason to pursue, e.g., liberation in their current state. Because of this, the satisfaction of the concentration camp victims' past desires will fail to benefit them. But then it will remain the case that the desire theorist is forced to conclude that liberation is no longer a benefit for these individuals. The problem persists.

Moreover, the desire theorist remains unable to vindicate the intuition that the concentration camp victims are badly off. According to the view we are now considering, what justifies the belief that these individuals are very badly off is that they have numerous past desires, all of which are currently being frustrated. But suppose I once had a desire to be an astronaut. In my current state, achieving this dream is a matter of complete indifference to me. Am I harmed by the frustration of a desire I long ago discarded? It seems to me that the answer is plainly "no." The cessation of a past desire cancels the possibility that its frustration might harm me. To suppose otherwise is to suppose that I am beset by a whole panoply of harms arising from the frustration of discarded past desires. Indeed, it seems that the piece of common advice expressed, for example, in Epicurus's Letter to Menoeceus - that one ought to minimize one's desire set (that is, abandon desires the satisfaction of which will be difficult or subject to chance), would be in vain were it the case that abandoned desires could still harm us.

Masked desires. Some may object that it is not plausible to see depression as causing a loss of desire; rather, depression merely prevents one's desires from manifesting. In other words, depression masks desire. The depressed individuals in the concentration camps are still disposed to, say, feel pleasure

12 Parfit (1984: 157) provides the example of his past - but since extinguished - desire to become a poet. He argues that it would be strange to claim that he has any reason to write poetry now, given that he "no longer [has] even the slightest desire to do so." 
when they think about being freed. They may even retain the disposition to be motivated to do what they can to bring about that goal. Yet their depression is such that these dispositions cannot manifest.

To make this objection clearer, we need to introduce a distinction between standing and occurrent desires. Call a desire occurrent if it is such as to be "playing some role in one's psyche at the moment," and standing if it is not (Schroeder (2015)). A desire is "playing some role in one's psyche" if it is a desire one is consciously aware of, and if it is actively determining (at least in part) one's behavior. The hunger one feels as lunchtime approaches is an example of an occurrent desire. Alternatively, desires that "lie at the back of one's mind" (e.g., a desire for "a new pair of skates") are standing desires (ibid.).

The objection, then, is that the concentration camp victims retain standing desires, but that depression masks these desires, preventing them from manifesting (and in turn guiding behavior, etc.) And as evidence for this, note that, when individuals suffering from depression recover, the vast majority of their desires come back exactly as they were before. It would be something close to a miracle if these desires were simply rebuilt from scratch. The desires must have remained - dormant - all along. ${ }^{13}$

Now, some of this may be oversold: it is true that many desires come back, but many others do not; experiencing depression changes a person. Indeed, many etiological theories of depression hypothesize that its primary function lies in compelling an organism to relinquish desires that are not in the organism's best interest (Price et al. (1994); Nesse (2000); Rottenberg (2014)). Not only that, but recovery takes a long time and often proceeds in fits and starts. It may well be that on that long, slow road a person really is rebuilding many of his desires from scratch. So I do not think the "miracle" argument is dispositive.

But suppose that the desires really are masked. Is it good for a person to have her masked desires satisfied? Imagine a more mundane case of depression: for instance, let us suppose that I am mildly depressed and as a result have lost my taste for lasagna, my favorite food. By "lost my taste" I mean that my desire for lasagna is now masked: I no longer acknowledge the desire's presence, and it is unable to play a role in determining my behavior. ${ }^{14}$ You do not realize this, however, and, hoping to cheer me up, make lasagna for dinner. Now, if it is true that satisfying masked desires is good for us, then we ought to predict - all else equal - that when considering a description of a depressed person whose masked desire is satisfied, we will have the intuition that the

13 Thanks to an anonymous referee for providing this additional evidence for the masking objection (and for helping me see the force of the objection more clearly).

14 Additionally, we can add the further stipulation that the satisfaction of my masked desire fails to produce pleasure in me. The pleasure, too, is masked: when I taste the lasagna, I taste the cheesy richness of it, the acidity of the tomato sauce, and so forth, but these sensory experiences fail to be pleasurable. This stipulation allows us to include Heathwood's version of desire satisfactionism - according to which "pleasure is the subjective satisfaction of desire" (2006: 539) - among the targets of my example. 
person described is getting some benefit (though perhaps a small one). In addition, we ought to have the intuition when considering descriptions of depressed individuals having their masked desires frustrated that those people are receiving some (perhaps small) harm.

But I think this prediction is not borne out. When I reflect on the scenario just described - my depressed self sitting down to a meal I no longer profess even to want - it is hard for me to conclude that getting the lasagna is still good for me. (Or that it is any better for me than getting some other equally nutritious pasta dish for which I have never expressed a preference.) Intuitively, then, it seems that getting the lasagna is no longer a benefit, and thus that satisfying masked desires does not benefit a person. Now let us suppose that you fail to make lasagna at the last minute because you have to stay late at work. Is having my masked desire frustrated bad for me? Again, it seems not. So even if depression merely masks desire, it does not seem that this fact saves the desire theory. Of course, intuitions may differ here; perhaps there is a debunking story to be told that would explain why my intuitions about these cases are no mark against the desire theory. Maybe the benefit (or the harm) is simply too small, or maybe the cases are under-described. But absent such a debunking explanation I am forced to conclude that one cannot appeal to masked desires to explain what is good or bad for the severely depressed. ${ }^{15}$

Bite the bullet. But maybe we should not judge that this is such a terrible state to be in. Suppose the desire theorist simply bites the bullet and concedes that, on her theory, the individuals in the Nazi camps are in fact neither welloff nor badly off, for if they really are utterly without desire, then they are beyond the reach of welfare ascription. Now, it is important to see that the desire theorist would not be denying that a monstrous injustice has been done to these people. It certainly has. They have been gravely harmed. But once they reach the state Frankl describes, then they have ceased to be subjects of welfare. Nothing can go badly for them any longer.

But, as noted above, this seems too much to stomach; for my part I cannot come to believe that it would not benefit them to be freed or harm them to be beaten. In fact, when combined with the claim - not infrequently held that facts about welfare are the sole determinants of right action, biting the bullet implies that it is no longer wrong to beat the prisoners Frankl describes.

15 With that said, a question remains: how do we decide when a disposition has been lost as opposed to merely masked? We might point to changes in the properties which ground those dispositions. Suppose we drop a vase on a hard surface and it does not shatter. Upon examination, we find that the vase's newfound resilience coincides with some change in its microstructural properties. I take it that we might then have good reason to think that it has lost its disposition to shatter. Some cases of conative collapse are like the shatterproof vase: if one's total desirelessness is a result of neurological damage, for example, I think we should hold that the dispositional bases (of the individual's desires) have been radically changed, or even destroyed. If so, then no disposition remains. The desires are lost. My claim could then be restricted to only certain cases of absent desires - that is, those in which the dispositional bases have been radically altered or destroyed. If we still hold - as I think we should - that individuals in those circumstances are very badly off, then the desire view is still in trouble. 
But this is surely wrong; thus, desire theorists will be forced to abandon the otherwise tempting thesis of welfarism. The costs of holding on to a desirebased theory of welfare begin to multiply.

I think these consequences are highly implausible - so implausible, in fact, that we should reject the desire theory. Ultimately, I do not have a knockdown argument against the "bite the bullet" strategy. But insofar as you share - as I do - the intuition that these implications are unacceptable, then you will want to look for an alternative account of what makes our lives go well and badly. The desire theory can only say that absent desire is a neutral state, but it is not the only theory out there. Perhaps an objective list account, for instance, could do better (cf. Fletcher (2013); Rice (2013)). It might say that the concentration camp victims Frankl describes lack most - perhaps all - of the objective goods of life, and have many of the bads. So their state is very bad for them. And, of course, we might explore many other options.

\section{Conclusion}

I conclude that the problem I have identified in this paper shows that we should reject desire-based accounts of welfare. These theories hold that what determines our welfare are facts about our desires - and only that. The cases of conative collapse discussed above show that these theories have very implausible implications. They fail to accommodate the intuition that the individuals described in this paper are very badly off; indeed, they fail to accommodate the intuition that they are even welfare subjects at all. Since these implications are unacceptable, we should reject desire-based theories. Desire is not all there is to welfare. ${ }^{16}$

Ian Tully

Washington University in St. Louis

Department of Philosophy

iantully@wustl.edu

16 Many thanks to John Doris, Julia Driver, Charlie Kurth, Jason Gardner, Mark Piper, Dylan Doherty and the two anonymous referees for their extremely helpful feedback on previous drafts of this paper. The paper also greatly benefited from discussions at the 2016 meeting of the Society for Philosophy and Psychology and the 2016 Great Plains Philosophy Symposium. 


\section{References}

American Psychiatric Association (2013) Diagnostic and Statistical Manual of Mental Disorders, 5th ed., Washington, D.C.

Andrews, P. and Thompson, J. A. (2009) “The Bright Side of Being Blue," Psychological Review 116(3): 620-54.

Augustine (1996) Enchiridion on Faith, Hope, and Love, T. Hibbs, trans., Washington, D.C.: Regnery Publishing.

Bradley, B. (2009) Well-Being and Death, Oxford: Oxford University Press.

Brandt, R. B. (1966) "The Concept of Welfare," in S. R. Krupp, ed., The Structure of Economic Science, Englewood Cliffs, NJ: Prentice-Hall, pp. 257-76.

Brook, A. (2006) "Desire, Reward, Feeling: Commentary on Schroeder's Three Faces of Desire," Dialogue 45: 157-64.

Fletcher, G. (2013) “A Fresh Start for the Objective List Theory of Well-Being," Utilitas 25(2): 206-20.

Frankfurt, H. (1971) "Freedom of the Will and the Concept of a Person," Journal of Philosophy 68(1): 5-20.

Frankl, V. (1986) The Doctor and the Soul, New York: Random House.

Ghaemi, N. (2013) On Depression: Drugs, Diagnosis, and Despair in the Modern World, Baltimore, MD: Johns Hopkins University Press.

Haybron, D. (2008) The Pursuit of Unhappiness, Oxford: Oxford University Press.

Heathwood, C. (2015) "Desire-Fulfillment Theory," in G. Fletcher, ed., The Routledge Handbook of Philosophy of Well-Being, New York: Routledge, pp. 135-47.

(2011) "Desire-Based Theories of Reasons, Pleasure, and Welfare," in R. Shafer-Landau, ed., Oxford Studies in Metaethics, Vol. 6, Oxford: Oxford University Press.

(2006) "Desire Satisfactionism and Hedonism," Philosophical Studies 128: 539-63.

(2005) “The Problem of Defective Desires," Australasian Journal of Philosophy 83: 487-504.

Hobbes, T. (1994/1651) Leviathan, E. Curley, trans., Indianapolis, IN: Hackett.

Kagan, S. (2015) "An Introduction to Ill-Being," in M. Timmons, ed., Oxford Studies in Normative Ethics, Oxford: Oxford University Press.

Li, Y., Mou, X., Jiang, W., et al. (2015) "A Comparative Study of Anhedonia Components Between Major Depression and Schizophrenia in Chinese Populations," Annals of General Psychiatry 14: 24.

Lin, E. (2016) "The Subjective List Theory of Well-Being," Australasian Journal of Philosophy 94(1): 99-114.

The Multi-Society Task Force on PVS (1994) "Medical Aspects of the Persistent Vegetative State," New England Journal of Medicine 330: 1499-1508.

Nakonezny, P., Carmody, T., Morris, D., Kurian, B. and Trivedi, M. (2010) "Psychometric Evaluation of the Snaith-Hamilton Pleasure Scale in Adult Outpatients with Major Depressive Disorder," International Clinical Psychopharmacology 25: 328-33.

Nesse, R. (2000) “Is Depression an Adaptation?" Archives of General Psychology 57(1): 14-20.

Panaioti, A. (2013) Nietzsche and Buddhist Philosophy, Cambridge: Cambridge University Press.

Parfit, D. (1984) Reasons and Persons, Oxford: Oxford University Press.

Portmore, D. (2007) "Desire Fulfillment and Posthumous Harm," American Philosophical Quarterly 44(1): 27-38.

Price, J., Sloman, L., Gardner, R. Jr., Gilbert, P. and Rohde, P. (1994) “The Social Competition Hypothesis of Depression," British Journal of Psychiatry 164(3): 309-15.

Railton, P. (1986) "Facts and Values," Philosopbical Topics 14(2): 5-31.

Rawls, J. (1971) A Theory of Justice, Cambridge, MA: Harvard University Press.

Rice, C. (2013) "Defending the Objective List Theory of Well-Being," Ratio 26(2): 196-211.

Rosati, C. (1995) "Persons, Perspectives, and Full-Information Accounts of the Good," Ethics 105(2): 296-325.

Rottenberg, J. (2014) The Depths: The Evolutionary Origins of the Depression Epidemic, New York: Basic. 
Schroeder, T. (2015) "Desire," in E. N. Zalta, ed., Stanford Encyclopedia of Philosophy (summer 2015 edition), plato.stanford.edu/archives/sum2015/entries/desire. (2006) "Desire," Philosophy Compass 1(6): 631-39.

(2004) Three Faces of Desire, Oxford: Oxford University Press.

Sherdell, L., Waugh, C. and Gotlib, I. (2012) "Anticipatory Pleasure Predicts Motivation for Reward in Major Depression,” Journal of Abnormal Psychology 121(1): 51-60.

Singer, P. (1979) Practical Ethics, Cambridge: Cambridge University Press.

Solomon, A. (2008) "Depression, Too, Is a Thing with Feathers," Contemporary Psychoanalysis 44(4): 509-30

Treadway, M. and Zald, D. (2011) "Reconsidering Anhedonia in Depression: Lessons from Translational Neuroscience," Neuroscience and Biobehavioral Reviews 35(3): 537-55. 